Journal of

Arid

ELSEVIER

\title{
Conservation of prairie dog ecosystem engineering may support arthropod beta and gamma diversity
}

\author{
R.K. Bangert*, C.N. Slobodchikoff \\ Department of Biological Sciences, Northern Arizona University, P. O. Box 5640, Flagstaff, AZ 86011-5640, USA
}

Received 17 November 2005; received in revised form 13 January 2006; accepted 19 January 2006

Available online 7 March 2006

\begin{abstract}
Ecosystem engineering by animals can create new habitats and increase the heterogeneity of the habitat mosaic that in turn can increase plant and animal diversity. Prairie dogs in North America alter both the above- and below-ground structure of the landscape and create novel habitats in grassland ecosystems. The ground-dwelling arthropod community associated with Gunnison's prairie dog modified habitats is compositionally different from that found in the surrounding grassland. Individual arthropod families and species have different distributions in both active prairie dog towns and inactive towns, compared to unmodified grasslands. These different responses to ecosystem engineering increase beta (between-habitat) and gamma (regional) diversity. This study suggests that simple measures of alpha diversity (species richness) may not adequately quantify overall diversity and that measures of beta diversity may be necessary to assess the role of prairie dogs as keystone engineers. Thus, conservation of prairie dogs and the engineering process may have positive effects for numerous species both locally and regionally.

(C) 2006 Elsevier Ltd. All rights reserved.
\end{abstract}

Keywords: Arthropod assemblage; Conservation; High desert grasslands; Ecosystem engineering; Gunnison's prairie dog; Keystone species; Petrified Forest National Park

\section{Introduction}

A critical issue in ecology is to determine the mechanisms behind the patterns of community assemblages. Once these mechanisms are better understood conservation

\footnotetext{
${ }^{*}$ Corresponding author. Tel.: + 19287740814 .

E-mail addresses: randy.bangert@nau.edu (R.K. Bangert), con.slobodchikoff@nau.edu (C.N. Slobodchikoff).
} 
biologists will better be able to prioritize conservation efforts. Two relevant and important concepts in conservation theory are keystone species and ecosystem engineers (Lomolino and Smith, 2003). Keystone species confer inordinate effects relative to their abundance or provide unique services (Power et al., 1996; Kotliar, 2000). Ecosystem engineers modify their habitat and these modifications may have positive or negative effects on other species (Jones et al., 1997). Although the keystone concept can be contentious (Stapp, 1998; Miller et al., 2000), as more studies are published it is clear that ecosystem engineering can be one mechanism that confers keystone status to a species (e.g. Lomolino and Smith, 2003) through the impact that they have on ecosystems (Jones et al., 1994, 1997; Brown, 1995; Kotliar, 2000). These effects can have far-reaching consequences that can affect not only ecological associations, but also the behavior of animals within an ecosystem. For example, we have recently shown that keystone-engineering influences landscape structure, which then in turn affects animal movement behavior (Bangert and Slobodchikoff, 2000, 2004).

A major class of effects comes in the form of mechanical ecosystem engineering where an organism modifies or creates habitat through its activities (e.g. beaver; Wright et al., 2002). For example, the activities of pocket gophers can have ecosystem level effects that influence plant diversity at small scales (Huntly and Inouye, 1988; Martinsen et al., 1990) and influence the distribution of aspen at large scales (Cantor and Whitham, 1989). Other examples include leaf-modifying insects whose structures enhance richness and abundance of inquilines and other arthropods (Martinsen et al., 2000; Lill and Marquis, 2003), and kangaroo rat mounds that influence the distribution of arthropods and vertebrates (Hawkins and Nicoletto, 1992). If the ecosystem engineer is rare, its overall effect may be large relative to its biomass and therefore provides a unique ecological service and can be classified as a keystone species (Power et al., 1996; Kotliar, 2000). Consequently, ecosystem engineering can have important conservation consequences by creating a landscape mosaic that influences the structure of vertebrate communities and increases the richness of avian species of conservation concern (Lomolino and Smith, 2003; Smith and Lomolino, 2004).

Ecosystem engineering has been demonstrated for two species of prairie dogs (Sciuridae: Cynomys spp.) in North America (Weltzin et al., 1997a, b; Ceballos et al., 1999; Bangert and Slobodchikoff, 2000), but concerns have been raised about the strength of the evidence supporting prairie dogs as keystones based on species associations (Stapp, 1998). Although the effects prairie dogs have on soils and plants is well understood (Carlson and White, 1987; Whicker and Detling, 1988; Munn, 1993; Weltzin et al., 1997a, b), only recently has evidence for the relationship between prairie dogs and faunal communities been well documented (e.g. Lomolino and Smith, 2003; Smith and Lomolino, 2004). Previously most work has been conducted on the functional relationships between prairie dogs and a few charismatic vertebrates of concern (Knowles et al., 1982; Krueger, 1986; Clark et al., 1989; Oldemeyer et al., 1993; Desmond et al., 1995; Desmond and Savidge, 1996; Kotliar et al., 1999), and these studies have focused on associations with the black-tailed prairie dog, C. ludovicianus, in mixed and short grass prairie (but see Davidson et al., 1999). However, there are five species of prairie dogs that occupy a range of grassland habitat types in the western Great Plains and Intermountain West from Canada to Mexico (Goodwin, 1995; Hoogland, 1995, p. 12) potentially resulting in region-wide ecosystem engineering effects with large-scale conservation implications.

In this study, we investigate the relationship between the Gunnison's prairie dog (C. gunnisoni) and a grassland arthropod community, for three reasons. First, prairie dogs have significant above- and below-ground ecosystem level impacts (Vogel et al., 1973; 
Carlson and White, 1987; Munn, 1993; Ceballos et al., 1999; Bangert and Slobodchikoff, 2000). Second, because arthropods represent over half of worldwide multi-cellular biodiversity (Crawford, 1981, 1991), arthropods are important ecosystem components (Seastedt, 1984; Kremen et al., 1993; Anderson, 1995; Parmelee, 1995), and little work has been done on the relationship between prairie dogs and arthropod communities (e.g. O'Meilia et al., 1982). Third, since prairie dog ecosystem engineering has been shown to have a positive effect on the richness and structure of vertebrate communities of conservation concern (Lomolino and Smith, 2003; Smith and Lomolino, 2004), it is important to quantify the relationship between prairie dog engineering and lower trophic levels. We use a comparative approach to take advantage of a natural experiment (sensu Diamond, 1986), and make the following predictions. Prairie dog habitat modification leads to: (1) differential responses by individual arthropod species to prairie dog-modified habitats; (2) this results in high beta (between habitat) diversity in arthropod community structure between prairie dog towns and unmodified grasslands; (3) high levels of beta diversity result in greater species richness across the landscape (gamma diversity).

\section{Materials and methods}

\subsection{Study site}

This work was conducted on the high desert grasslands (1600-1750 m above sea level) at Petrified Forest National Park (PEFO), Arizona, USA, during 1996 and 1997 from 1 June through 30 July. Petrified Forest has an average annual precipitation of $24.4 \mathrm{~cm}$ and average high temperatures ranging from $0.8^{\circ} \mathrm{C}$ in January to $23.5^{\circ} \mathrm{C}$ in July. Precipitation exhibits a single peak in July and August due to the summer monsoon. The vegetation at PEFO is characterized as shrub-steppe dominated by the large shrubs Atriplex canescens, Artemisia filifolia, and Ar. Biglovii, and the smaller At. jonesii and At. confertifolia. The grasses Bouteloua gracilis, Stipa hymenoides, and Sporobolus spp. are common (Kierstead, 1981).

\subsection{The ecosystem engineer}

The Gunnison's prairie dog (Cynomys gunnisoni Hollister) is a medium sized $(675-1350 \mathrm{~g})$ ground squirrel in the family Sciuridae. This species is found on the Colorado Plateau extending across four states in North America: Arizona, Colorado, New Mexico, and Utah (Fitzgerald et al., 1994; Goodwin, 1995). Gunnison's prairie dogs are colonial and social animals (Slobodchikoff, 1984; Hoffmeister, 1986; Fitzgerald et al., 1994), and prairie dog colonies, or towns, are conspicuous features of North American grassland ecosystems. Activities of prairie dogs include alteration of soil chemistry and extensive soil movement (Carlson and White, 1987; Munn, 1993; Ceballos et al., 1999), herbivory (Whicker and Detling, 1988), and granivory (Shalaway and Slobodchikoff, 1988), resulting in significant changes in the fractal dimension of landscape spatial structure and shrub distribution (Bangert and Slobodchikoff, 2000).

\subsection{Experimental design}

This study took advantage of a natural experiment (Diamond, 1986) where the landscape was manipulated by the Gunnison's prairie dog and $100 \%$ of the prairie dogs 
were extirpated from two of the five prairie dog towns by plague (Yersina pestis; Cully, 1989; Fitzgerald, 1993) 15 months prior to the beginning of this study resulting in a BACIstyle experiment $(\mathrm{B}=$ before, $\mathrm{A}=$ after intervention, $\mathrm{C}=$ control, and $\mathrm{I}=$ Intervention; Stewart-Oaten et al., 1986, 1992). Natural experiments offer an important opportunity for study because it is both difficult and unethical to manipulate animals and landscapes at large scales, and this is particularly relevant to conservation studies (Farnsworth and Rosovsky, 1993; Brown, 1995; Lomolino and Smith, 2003). There were three levels of natural habitat variability in this study: (1) habitats with no modification by prairie dogs representing before and control effects (B and C; grasslands), (2) habitats previously modified by prairie dogs but with no prairie dogs present representing the after intervention effect (A; inactive towns), and (3) habitats with prairie dogs present (active towns) represent the intervention (I) aspects of a BACI-type experimental design.

In 1996 three active prairie dog towns, two inactive prairie dog towns, and five grassland habitats were sampled for ground-dwelling arthropods. One active site and a nearby grassland site were sampled concurrently for five consecutive days, and then an inactive site and another grassland site were sampled concurrently. Additional active, inactive, and grassland sites were alternately sampled in order to reduce temporal pseudoreplication (Hurlbert, 1984) resulting in a total of 2500 trap days. Each grassland site was $<1 \mathrm{~km}$ from the nearest prairie dog town. In 1997 access to towns was restricted because of archeological concerns, so increased effort was concentrated at one active town, one inactive town, and a grassland site located approximately $6 \mathrm{~km}$ in-between the two prairie dog towns. All three sites were sampled concurrently for 19 days resulting in 2850 trap days. During both years 50 pitfall traps were distributed randomly over 1 ha at each site. Arthropods were identified to family, and we feel that this provides good resolution and a conservative approach for this study. For example, at the family level most species can be categorized by trophic status, with the exception of the ants (Formicidae).

Traps were $12 \mathrm{oz}$. Solo ${ }^{\circledR}$ plastic cups nested in $16 \mathrm{oz}$. cups set flush with the ground surface. Each trap had an elevated plywood lid for shade $\left(900 \mathrm{~cm}^{2}\right)$ to protect animals from the sun. Each morning, traps were checked, arthropod identification was determined to family level and the arthropods were counted and then released in a random direction $\approx 3 \mathrm{~m}$ from the trap. Large mobile animals were marked with a unique number to avoid recounting. Animals not identified to family were collected for later identification and "Day" was the sample unit used in the composition analysis. Since all traps in 1997 were sampled concurrently, we checked for temporal autocorrelation by examining residuals and the Durbin-Watson test indicating that there was no autocorrelation between days and therefore days were regarded as independent. Every site was subjected to the same sampling regime and the weather was consistent throughout the sampling period from 1 June through 30 July within each year. In 1997 the distance from each trap was quantified to the nearest burrow to assess the arthropod relationship with burrows.

\subsection{Differential effects of above-ground engineering}

\subsubsection{Unique taxa}

Ecosystem engineering hypotheses predict that some species will be positively affected and some negatively affected by mechanical engineering and subsequent habitat alteration 
(Jones et al., 1997). First, the number of unique taxa associated with prairie dog towns was quantified. Prairie dog towns were nested within the larger grassland landscape matrix of $\approx 37,851$ ha (we estimated that prairie dog towns comprise $<2 \%$ of the landscape area at PEFO). Therefore the null expectation was that the faunas associated with prairie dog towns would also be nested within the overall grassland arthropod family pool. To address this, the proportion of unique families contributed by individual prairie dog towns was assessed with single sample $t$-tests. Individual towns were compared to grasslands at three different scales: (1) versus the nearest grassland site of the same size, (2) versus all grassland sites pooled within the year that the prairie dog site was sampled, and (3) versus all grassland sites pooled across years. This resulted in a test that was increasingly biased in favor of the grassland family pool as grassland scale increased. For this analysis active and inactive towns were considered as the same treatment, resulting in seven replicate prairie dog towns. Under the null hypothesis that the prairie dog arthropod community is a perfectly nested subset of the larger regional grassland family pool, the proportion of unique families found on prairie dog habitats should be zero.

\subsubsection{Indicator taxa}

The occurrence of indicator taxa for each habitat was quantified with the software program INDVAL (Dufrêne and Legendre, 1997). Indicator taxa are determined by the distribution of individuals within each taxon across samples and treatments. The indicator value, $I$, indicates the percent predictability of sampling a particular taxon in a particular habitat type with $p$-values determined by Monte Carlo methods. For example, if ants were found in all samples within only one habitat type they would have an indicator value of $I=100.00$ for that habitat.

In order to assess the effects of above-ground engineering on community structure, the 1996 arthropod community was quantified at each site $(n=10)$ with nonmetric multidimensional scaling (NMDS; Minchin, 1987, 1999) and the community onedimensional solution ordination scores were regressed against the fractal dimension of each site (Anderson, 2001). Landscape fractal dimension was used as a measure of ecosystem engineering, where sites with large fractal dimensions were associated with heavily modified prairie dog habitats (Bangert and Slobodchikoff, 2000).

\subsection{Relationship with below-ground structures}

To assess the effects of below ground engineering, i.e. burrows, in 1997 we modeled the distribution of two abundant beetle species in the family Tenebrionidae and crickets in the family Gryllacrididae, and their relationship to prairie dog burrow proximity with loglinear regression (Agresti, 1996). In 1998, traps were placed at 1 and $5 \mathrm{~m}$ from burrow entrances. Pairs of traps were placed at random at a grassland site and randomly designated as the " $1 \mathrm{~m}$ " or " $5 \mathrm{~m}$ " traps. This was done because adding a burrow treatment to a grassland site was not permitted because of archaeological concerns in the Park. Additionally, at the community level Mantel tests were used to assess the relationship between abundance and community structure with distance from burrows. If burrows do not influence these animals, the null hypothesis predicts that traps at all distances from burrows will trap similar numbers of animals and have similar communities. 


\subsection{Community structure}

In this study we concentrate on beta diversity (community structure between habitats) because alpha diversities (e.g. species richness between habitats) may not be different but community structure can be very different (Bangert et al., 2005; Wimp et al., 2005). Beta diversity was assessed as dissimilarity in community structure between habitats, and was quantified with the powerful ordination technique, Canonical Analysis of Principal coordinates (CAP; Anderson and Willis, 2003) and the Bray-Curtis similarity coefficient (Bray and Curtis, 1957; Kruskal, 1964; Faith et al., 1987; Minchin, 1987; Clarke, 1993; Legendre and Legendre, 1998; Dungey et al., 2000). Additionally, pairwise comparisons were conducted between all treatments and randomization tests were used to determine $p$-values. These $p$-values are reported without any correction for multiple tests so that readers can make their own determination as to the strength of the treatment effects. CAP is appropriate for these data because the procedure corrects for the effect of taxa that are correlated across treatments. Finally, we use accumulation curves to assess the contribution of the prairie dog treatments to gamma, i.e. regional diversity.

\section{Results}

\subsection{Differential effects of above-ground engineering}

\subsubsection{Unique taxa}

Unique families were found in both prairie dog and grassland habitats. Prairie dog and grassland habitats contributed 6 and 10 unique families, respectively. Even though there were not consistent differences in richness between individual prairie dog towns and the nearest grassland site, at all scales prairie dog towns contributed more unique taxa than expected by chance if they were simple subsets of the grassland family pool (vs. nearest grassland: $t=6.78, \mathrm{df}=6 ; p=0.0005$; vs. grasslands pooled within year: $t=4.15, \mathrm{df}=6$; $p=0.003$; vs. all grasslands pooled across years: $t=1.91, \mathrm{df}=6 ; p=0.053$; Fig. 1a). For example, the 1997 ordered accumulation curve shows that prairie dog-modified habitats contribute families beyond the families found on grassland habitats even though there were no differences in richness among treatments (Fig. 1b; the 1996 accumulation curve was similar to the 1997 curve). These data suggest that prairie dog activities significantly affect this ground-dwelling arthropod community at different scales, and the quantification of beta diversity is as informative as alpha diversity ( $\mathrm{Su}$ et al., 2004).

\subsubsection{Indicator taxa}

There were several families that were significant indicators for each of the three habitat types in this study. The response by different families to different habitats was what might be expected. For example, the insect herbivore family, Cicadellidae, was almost 10 times more abundant on grasslands relative to prairie dog habitats $(z=4.50, p<0.0001)$, while the Scarabaeidae was 13 times more abundant on active prairie dog towns where scats were abundant $(z=3.09, p=0.001)$. Indicator value analysis suggests that over the course of this study, Cicadellidae were the only significant indicators of grasslands. Pholcidae, Mutillidae, Curculionidae, Cerambicidae, and Isopoda were significant indicators of inactive towns, and Salticidae, Gelichiidae, and Gryllidae were significant indicators of 


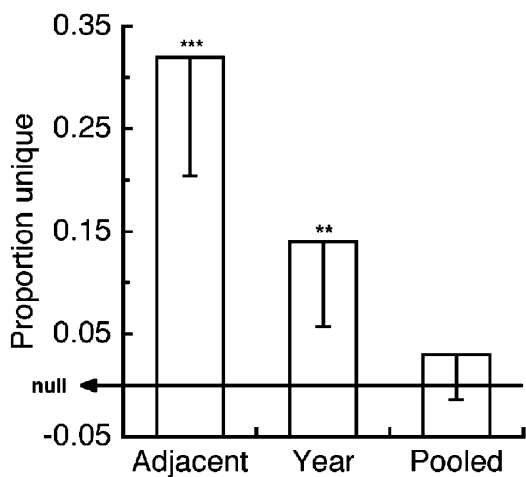

(a)

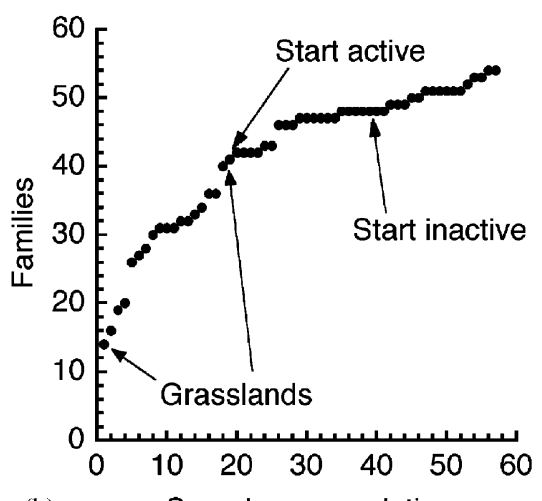

(b)

Sample accumulation

Fig. 1. (a) Mean proportion of unique families contributed to the grassland ecosystem by seven prairie dog towns at different scales. One-sample $t$-tests of these proportions on individual prairie dog towns versus the null hypothesis that prairie dog habitats are subsets of the greater grassland ecosystem with the proportion of unique families equal to zero. "Adjacent" is individual towns versus the nearest grassland site, "Year" is individual towns versus all grassland communities pooled for that year, and "Overall" is individual towns versus all grassland communities pooled across years, resulting in an increased bias, in favor of the null hypothesis, as grassland scale increases. Horizontal line represents the null hypothesis. Error bars represent the lower 95\% confidence interval, two asterisks indicates significance at $p<0.01$, and three asrterisks indicate $p<0.001$. (b) 1997 ordered accumulation curve (grasslands-active-inactive) of family richness where all three habitats had similar numbers of families, but active and inactive towns add unique families beyond what the grasslands contribute. The 1996 accumulation curve is similar to the 1997 accumulation curve.

Table 1

Arthropod families that were significant indicators of habitat types on the grasslands at Petrified Forest National Park, AZ, USA

\begin{tabular}{|c|c|c|c|c|c|c|c|}
\hline \multirow[b]{2}{*}{ Family } & \multicolumn{2}{|l|}{ Active } & \multicolumn{2}{|l|}{ Inactive } & \multicolumn{2}{|c|}{ Grasslands } & \multirow[t]{2}{*}{ Functional group } \\
\hline & IndVal & $t$-value & IndVal & $t$-value & IndVal & $t$-value & \\
\hline Salticidae & 19.2 & 3.24 & & & & & Predator \\
\hline Gryllidae & 16.6 & 4.18 & & & & & Herbivore \\
\hline Gelechiidae & 18.1 & 4.86 & & & & & Herbivore \\
\hline Pholcidae & & & 43.9 & 4.43 & & & Predator \\
\hline Isopoda & & & 21.4 & 4.20 & & & Omnivore \\
\hline Cerambicidae & & & 24.7 & 5.53 & & & Herbivore \\
\hline Curculionidae & & & 26.5 & 2.90 & & & Herbivore \\
\hline Mutillidae & & & 43.2 & 4.84 & & & Parasitoid \\
\hline Cicadellidae & & & & & 32.0 & 5.58 & Herbivore \\
\hline
\end{tabular}

active towns (Table 1). This analysis supports the hypothesis that different taxa respond differently to prairie dog engineering and this results in high arthropod beta diversity.

\subsection{Relationship with below-ground structures}

There was a relationship between below ground engineering (burrows) and three conspicuous taxa. The beetle Eleodes extricata had greater numbers on the inactive than 

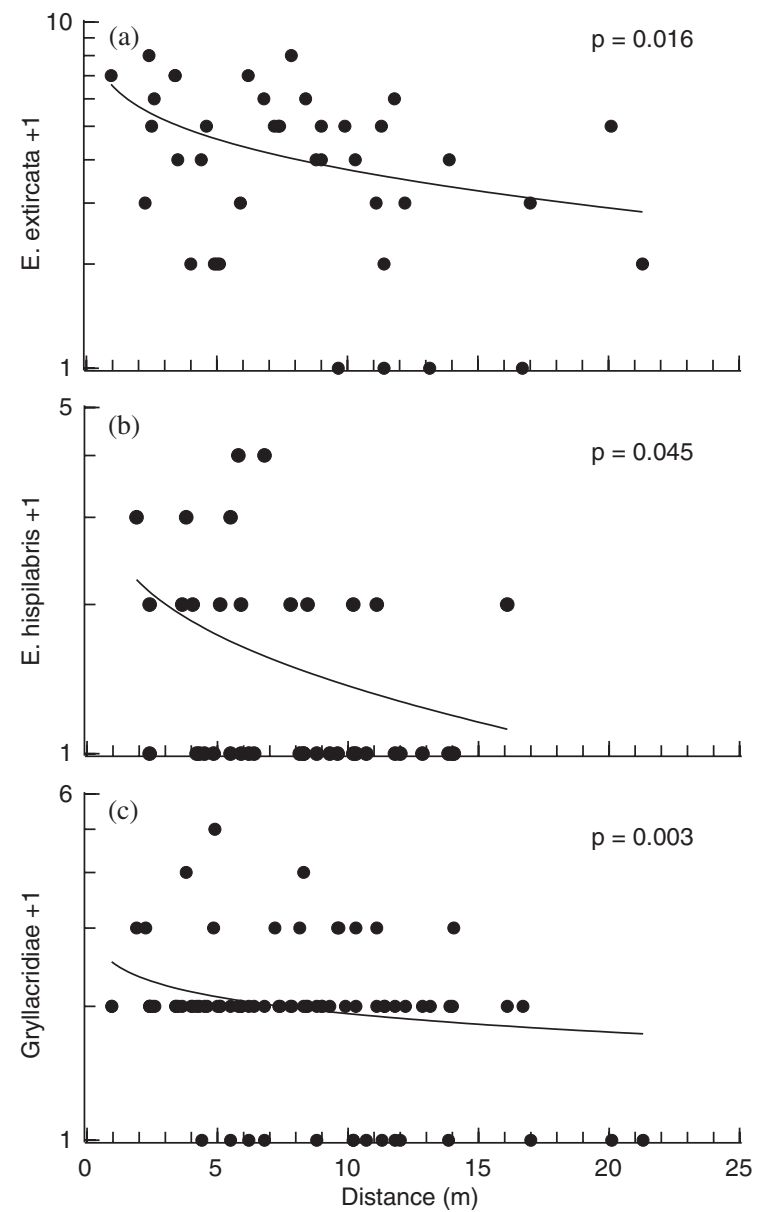

Fig. 2. Beetle and cricket correlations with prairie dog burrows modeled with loglinear regression. E. extricata was trapped more often closer to burrows on an inactive prairie dog town (a). E. hispilabris (b) and camel crickets (c) were trapped more often closer to burrows on both active and inactive towns.

active town $\left(\mathrm{df}=1, \chi^{2}=36.6, p<0.0001\right)$ and was trapped more often in close proximity to inactive prairie dog burrows ( $\log$ beetle $=1.673-0.046 \times$ distance, $p=0.01$, Fig. $2 \mathrm{a}$ ). E. hispilabris had equal numbers between both prairie dog habitats and was trapped closer to all burrows types ( $\log$ beetle $=0.492-0.023 \times$ distance, $p=0.045$, Fig. 2b). Gryllacridid crickets were also trapped more often closer to all burrow types (log cricket $=0.86-0.27 \times$ distance, $p=0.003$, Fig. 2c). In 1998 trapping frequencies for these three taxa were evaluated at 1 and $5 \mathrm{~m}$ from burrow entrances, and in pairs of traps on a grassland site. There were no crickets trapped on the grassland and $233 \%$ more crickets trapped in the $1 \mathrm{~m}$ traps than in the $5 \mathrm{~m}$ traps $\left(\chi^{2}=29.6 ; p=0.0001 ; \mathrm{df}=2\right)$. Likewise, there was only one beetle trapped on the grassland site and $135 \%$ more beetles trapped at $1 \mathrm{~m}$ than at $5 \mathrm{~m}$ from burrow entrances $\left(\chi^{2}=26.3 ; p=0.0001 ; \mathrm{df}=2\right)$. These data suggest that burrows are important to these animals. 

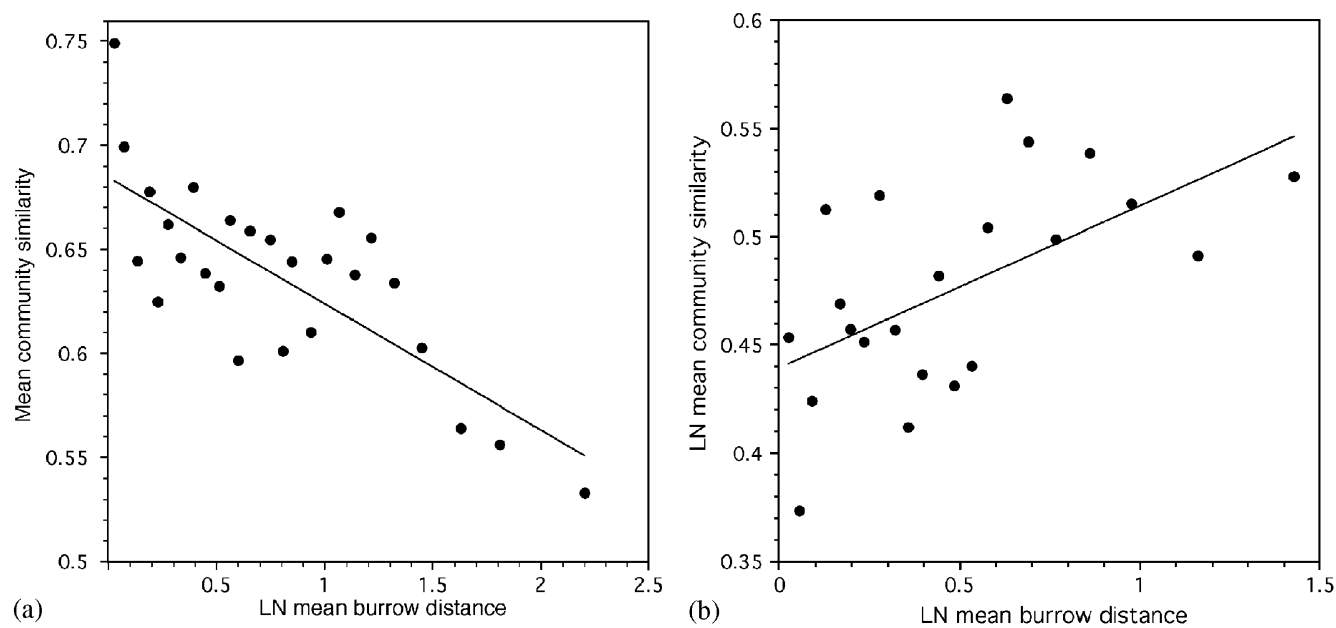

Fig. 3. Arthropod communities are more similar closer to burrows, on average, at the inactive prairie dog town (a), but show the opposite response at the active town where communities are more similar at greater distances from burrows (b). Community similarity is represented by the Bray-Curtis similarity coefficient and similarity in burrow distance is represented by Euclidean distance, where small distances represent communities that are more similar.

Community structure was similar at similar distances from burrows on the inactive town (Mantel $r=-0.3146$, Mantel $t=-3.44, p=0.0003, n=26$; Fig. 3a), and the pattern was opposite on the active town (Mantel $r=0.1897$, Mantel $t=1.91, p=0.03, n=22$; Fig. 3b). In other words, community structure changes with proximity to burrows differently between these two habitats, which suggests that there may be differences in burrow environments between active and inactive towns resulting in a habitat mosaic that increases beta diversity.

The above-ground engineering component showed that 22 families had significantly greater relative abundances among the three different habitats, but these were equally distributed (active $=8$; inactive $=7$, grass $=7$ ), suggesting that alpha diversity alone is not sufficient to characterize differences between treatments. This analysis also supports the hypothesis that ecosystem engineering affects taxa differently. Overall, $68 \%$ of these families showed a positive response to prairie dog engineered landscapes, inactive and active combined. At the community level habitats with similar landscape structures, measured by fractal dimension, had similar arthropod community structures $\left(r^{2}=0.4849\right.$, $p=0.025, F_{1,8}=7.53$; Fig. 4).

\subsection{Community structure}

Over 2 years of this study, 2315 arthropod individuals were distributed over 68 families in 5350 trap days. There were differences in community structure by habitat and a Canonical Analysis of Principal coordinates (CAP; Anderson and Willis, 2003) indicated that the arthropod community in each habitat was unique (1996: all pairwise $p \leqslant 0.002$, Fig. 5a; 1997: all pairwise $p \leqslant 0.0002$, Fig. 5b). 


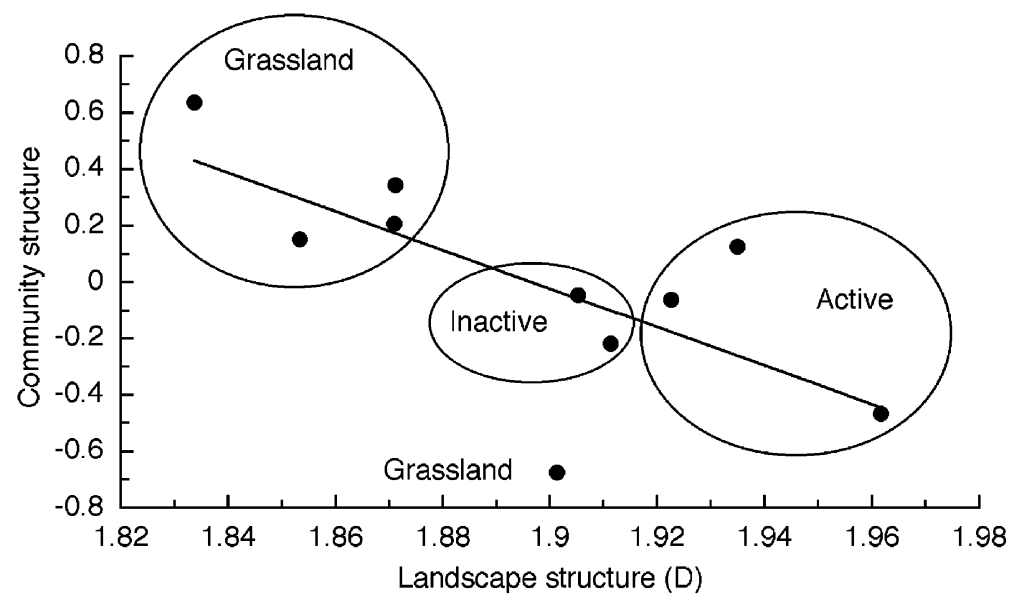

Fig. 4. Arthropod community structure at each site (1996) changes with an increase in prairie dog engineering. The mean landscape fractal dimension of each site is a measure of engineering, where large fractal dimension indicates more intensive prairie dog activity. Arthropod community structure is based on the one-dimensional NMDS ordination scores, which place a multivariate community into one-dimensional Euclidean space with no a priori expectation on the slope of the relationship, but rather, community composition changes with engineering. Site treatments are encompassed by ellipses.

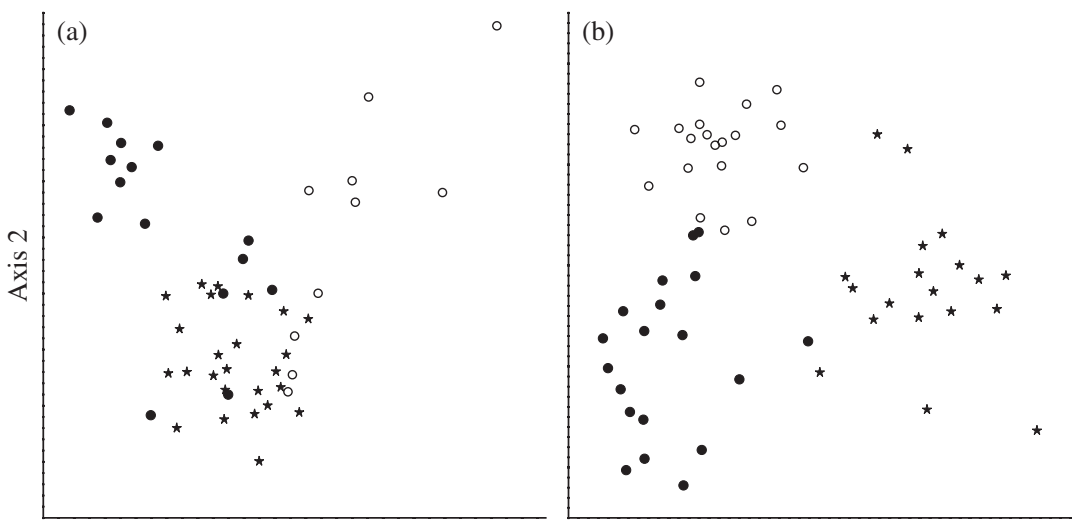

Axis 1

Fig. 5. Canonical analysis of principal coordinates (CAP) of community composition where axes are unit-less and only serve to place points in ordination space; points close together are more similar than points that are more distant. (a) Arthropod community structure at 10 sites $\times 5$ days for 1996, and (b) for the 3 sites $\times 19$ days in 1997 . In both years the communities are significantly dissimilar across the three treatments. Active $=\mathbf{0}$; Inactive $=0$; Grasslands $=\star$.

\section{Discussion}

This is the first community-level study that examined the effects of ecosystem engineering by the Gunnison's prairie dog on arthropods, comparing active and inactive prairie dog towns with unmodified grasslands. In this study both above- and below-ground 
prairie dog engineering was significantly correlated with several arthropod species, and with community structures between each prairie dog habitat and the grassland matrix. The high beta diversity associated with the presence of prairie dogs resulted in an increase in gamma diversity within Petrified Forest National Park. For example, family richness was the same for the three habitats and yet an analysis of community structure indicated that there were distinct communities associated with the three habitat types in this study. High beta diversity is likely due to individual responses by different taxa to prairie dog engineering as predicted by one ecosystem engineering hypothesis (Jones et al., 1997). For example, prairie dogs may be contributing detritus (see Hawkins and Nicoletto 1992 with reference to kangaroo rat contribution of detritus), thus detritivores (e.g. Scarabaeidae rolling scats, pers. obs.) may become more abundant in prairie dog modified habitats, whereas herbivory by prairie dogs may exclude insect herbivores such as the Cicadellidae in the active towns. We found that there were a significant proportion of unique families associated with both types of prairie dog habitats over a large range of scales. Thus, without prairie dogs there would be no beta diversity component and gamma diversity would likely be $33 \%$ lower (Fig. 1b). On the high desert grasslands of Petrified Forest, prairie dog engineering appears to create a habitat mosaic that significantly influences the arthropod community at several scales. This suggests that prairie dogs play a unique role in this desert grassland ecosystem and therefore, they may be a keystone to this faunal community (e.g. Kotliar, 2000). We expect that if a finer resolution of taxa were used, e.g. the species level, these patterns would become stronger.

We used the fractal dimension of landscape structure as a measure of above-ground ecosystem engineering (Bangert and Slobodchikoff, 2000) and found that sites with similar levels of ecosystem engineering also had similar community structures. An alternative hypothesis is that the presence of prairie dogs on the active town inhibits arthropod activity. We do not favor this hypothesis because insects are not a significant component of prairie dog diets (Fagerstone et al., 1981; Shalaway and Slobodchikoff, 1988). Another alternative hypothesis is that arthropods are responding to changes in floristic structure due to prairie dog activities; however, we did not test this hypothesis, although, changes in floristic structure have been shown to result from prairie dog engineering activities (Archer et al., 1987; Whicker and Detling, 1988, 1993; Weltzin et al., 1997a, b).

Because there were different responses to burrows among arthropod species and communities between the active and inactive towns, this suggests that there may be differences in burrow environments between these towns (see Hawkins and Nicoletto). One hypothesis is that burrows on the active town are maintained in an open condition facilitating burrow self-ventilation resulting in lower levels of relative humidity (Vogel et al., 1973), potentially affecting arthropod osmoregulation (e.g. Riddle et al., 1976; Slobodchikoff, 1983; Whicker and Tracy, 1987; Parmenter et al., 1989), whereas the burrow entrances on inactive towns become closed with time (pers. obs.) thus inhibiting the ventilation process, resulting in a more equable environment (e.g. Schmidt-Nielson and Schmidt-Nielson, 1950).

The above- and below-ground results support the hypothesis that ecosystem engineering by the Gunnison's prairie dog provides a unique ecological service (Kotliar, 2000) that may enhance arthropod diversity. These results do not suggest that we can eliminate prairie dogs in order to create inactive town habitats, but rather support the hypothesis that prairie dog engineering results in a mosaic of habitat conditions, i.e. landscape heterogeneity, that increase beta and gamma diversity (e.g. active habitats also contain 
unique species). All species of prairie dogs are suffering dramatic population declines due to human activities, persecution, and the exotic epizootic plague, $Y$. pestis (Miller and Cully, 2001). Thus, prairie dogs require conservation attention and consideration as threatened species, as well as their importance in creating habitat mosaics that are important to many invertebrate and vertebrate species (Lomolino and Smith, 2003).

Prairie dog towns are important to many vertebrate species of concern (e.g. black-footed ferrets, bald eagles, ferruginous hawks, and burrowing owls) and influence mammal, herptile, and avian community structure (Lomolino and Smith, 2003; Smith and Lomolino, 2004). This is the first community level study to demonstrate that prairie dog habitats are also important to invertebrates. This is of conservation concern because the diversity of animals at the base of the food web has the potential for a bottom-up contribution to ecosystem function, and the diversity of taxa at higher levels may be mediated by prairie dog engineering. For example, other studies have found higher abundance of small mammals (O'Meilia et al., 1982; Agnew et al., 1986, 1988), significant differences in mammal community structure, and higher diversity of vertebrate species of conservation concern (Lomolino and Smith, 2003; Smith and Lomolino, 2004) on blacktailed prairie dog towns compared to adjacent grasslands. Most of the species in these studies incorporate arthropods in their diet and this provides the testable hypothesis that diversity at lower trophic levels, i.e. invertebrates, may positively affect diversity at higher trophic levels, i.e. vertebrates, on prairie dog towns. One mechanism for greater vertebrate diversity may be due to high arthropod beta diversity, resulting in a more heterogeneous feeding niche space for vertebrate insectivores.

The prairie dogs' influence on soils and plants (Carlson and White, 1987; Whicker and Detling, 1988, 1993; Munn, 1993) should be sufficient to classify prairie dogs as keystone species. This study is consistent with the hypothesis that prairie dogs may be keystone species to animal communities as a result of their engineering activities (Ceballos et al., 1999; Kotliar et al., 1999; Kotliar, 2000; Miller et al., 2000). As in the grasslands of the Great Plains, the continued loss of prairie dog habitat and the homogenization of this high desert grassland will result in the decline of arthropod diversity, and potentially vertebrate diversity, similar to that described by Lomolino and Smith (2003). This adds support to the more holistic approach of habitat conservation as a more efficient conservation strategy (e.g. Bangert et al., 2005) through the protection of these ecosystem engineers (e.g. Simberloff, 1998) and their extended effects (Smith and Lomolino, 2004), rather than a continuation of the practice of conservation triage where numerous species become threatened due to the loss of the habitat mosaic created and maintained by this class of organisms.

\section{Acknowledgements}

We would like to thank J. Bailey, G.D. Martinsen, V.J. Meretsky, P.W. Price, J.A. Schweitzer, J.A. Smallwood, D.M. Wagner, G.M. Wimp, and several anonymous reviewers for helpful comments on previous drafts of this paper. We appreciate the efforts of M. Hellickson, W. Grether, and M. DePoy at Petrified Forest National Park for encouraging and facilitating ecological work in the Park and J.C. Soborio for help with arthropod identification. This work was in part funded by grants provided by the Petrified Forest Museum Association to RKB. 


\section{References}

Agnew, W., Uresk, D.W., Hansen, R.M., 1986. Flora and fauna associated with prairie dog colonies and adjacent ungrazed mixed-grass prairie in western South Dakota. Journal of Range Management 39, $135-139$.

Agnew, W., Uresk, D.W., Hansen, R.M., 1988. Arthropod Consumption by Small Mammals on Prairie Dog Colonies and Adjacent Ungrazed Mixed Grass Prairie in Western South Dakota. Habitat use and Management of Small Mammals and Amphibians. USDA Forest Service, Washington, DC.

Agresti, A., 1996. An Introduction to Categorical Data Analysis. Wiley, New York.

Anderson, J.M., 1995. Soil organisms as engineers: microsite modulation of macroscale processes. In: Jones, C.G., Lawton, J.H. (Eds.), Linking Species and Ecosystems. Chapman \& Hall, New York, pp. 94-116.

Anderson, M.J., 2001. A new method for non-parametric multivariate analysis of variance. Australian Journal of Ecology 26, 32-46.

Anderson, M.J., Willis, T.J., 2003. Canonical analysis of principal coordinates: a useful method of constrained ordination for ecology. Ecology 84, 511-525.

Archer, S., Garrett, M.G., Detling, J.K., 1987. Rates of vegetation change associated with prairie dog (Cynomys ludovicianus) grazing in North American mixed-grass prairie. Vegetation 72, 159-166.

Bangert, R.K., Slobodchikoff, C.N., 2000. The Gunnison's prairie dog structures a high desert grassland landscape as a keystone engineer. Journal of Arid Environments 46, 357-369.

Bangert, R.K., Slobodchikoff, C.N., 2004. Prairie dog engineering indirectly affects beetle movement behavior. Journal of Arid Environments 56, 83-94.

Bangert, R.K., Turek, R.J., Martinsen, G.D., Wimp, G.M., Bailey, J.K., Whitham, T.G., 2005. Benefits of conservation of plant genetic diversity on arthropod diversity. Conservation Biology 19, 379-390.

Bray, J.R., Curtis, J.T., 1957. An ordination of the upland forest communities of southern Wisconsin. Ecological Monographs 27, 325-349.

Brown, J.H., 1995. Organisms as engineers: a useful framework for studying effects on ecosystems? Trends in Ecology and Evolution 10, 51-52.

Cantor, L.F., Whitham, T.G., 1989. Importance of belowground herbivory: pocket gophers may limit aspen to rock outcrop refugia. Ecology 70, 962-970.

Carlson, D.C., White, E.M., 1987. Effects of prairie dogs on mound soils. Journal of the Soil Science Society of America 51, 389-393.

Ceballos, G., Pacheco, J., List, R., 1999. Influence of prairie dogs (Cynomys ludovicianus) on habitat heterogeneity and mammalian diversity in Mexico. Journal of Arid Environments 41, 161-172.

Clark, T.W., Hinckley, D., Rich, T. (Eds.), 1989. The prairie dog ecosystem: managing for biological diversity. Wildlife Technical Bulletin 2, Montana Bureau of Land Management, Billings.

Clarke, K.R., 1993. Non-parametric multivariate analyses of changes in community structure. Australian Journal of Ecology 18, 117-143.

Crawford, C.S., 1981. The Biology of Desert Invertebrates. Springer, Berlin.

Crawford, C.S., 1991. The community ecology of macroarthropod detritivores. In: Polis, G.A. (Ed.), The Ecology of Desert Communities. University of Arizona Press, Tucson, pp. 89-112.

Cully Jr., J.F., 1989. Plague in prairie dog ecosystems: importance for black-footed ferret management. In: Clark, T.W., Hinckley, D., Rich, T. (Eds.), The Prairie Dog Ecosystem: Managing for Biological Diversity. Wildlife Technical Report 2. Montana Bureau of Land Management, Billings, pp. 47-55.

Davidson, A.D., Parmenter, R.R., Gosz, J.R., 1999. Responses of small mammals and vegetation to a reintroduction of Gunnison's prairie dogs. Journal of Mammalogy 80, 1311-1324.

Desmond, M.J., Savidge, J.A., 1996. Factors influencing burrowing owl nest densities and numbers in western Nebraska. American Midland Naturalist 136, 143-148.

Desmond, M.J., Savidge, J.A., Siebert, T.F., 1995. Spatial patterns of burrowing owl (Speotyto cunicularia) nests within black-tailed prairie dog (Cynomys ludovicianus) towns. Canadian Journal of Zoology 73, 1375-1379.

Diamond, J., 1986. Overview: laboratory experiments, field experiments, and natural experiments. In: Diamond, J., Case, T.J. (Eds.), Community Ecology. Harper and Row, New York, pp. 3-22.

Dufrêne, M., Legendre, P., 1997. Species assemblages and indicator species: the need for a flexible asymmetrical approach. Ecological Monographs 67, 345-366.

Dungey, H.S., Potts, B.M., Whitham, T.G., Li, H.-F., 2000. Plant genetics affects arthropod community richness and composition: evidence from a synthetic eucalypt hybrid population. Evolution 54, 1938-1946. 
Fagerstone, K.A., Tietjen, H.P., Williams, O., 1981. Seasonal variation in the diet of black-tailed prairie dogs. Journal of Mammalogy 62, 820-824.

Faith, D.P., Minchin, P.R., Belbin, L., 1987. Compositional dissimilarity as a robust measure of ecological distance. Vegetation 69, 57-68.

Farnsworth, E.J., Rosovsky, J., 1993. The ethics of ecological field experimentation. Conservation Biology 7, $463-472$.

Fitzgerald, J.P., 1993. The ecology of plague in Gunnison's prairie dogs and suggestions for the recovery of blackfooted ferrets. In: Oldemeyer, J.L., Biggins, D.E., Miller, B.J., Crete, R. (Eds.), Proceedings of the Symposium on the Management of Prairie dog Complexes for the Reintroduction of the Black-Footed Ferret. US Department of the Interior: Fish and Wildlife Service, Washington, DC, pp. 50-58 Biological Report 13.

Fitzgerald, J.P., Meaney, C.A., Armstrong, D.M., 1994. Mammals of Colorado. Denver Museum of Natural History and University Press of Colorado, Denver.

Goodwin, T.H., 1995. Pliocene-Pleistocene biogeographic history of prairie dogs, genus Cynomys (Sciuridae). Journal of Mammalogy 76, 100-122.

Hawkins, L.K., Nicoletto, P.F., 1992. Kangaroo rat burrows structure the spatial organization of grounddwelling animals in a semiarid grassland.

Hoffmeister, D.F., 1986. Mammals of Arizona. University of Arizona Press and the Arizona Game and Fish Department, Tucson.

Hoogland, J.L., 1995. The Black-Tailed Prairie Dog: Social Life of a Burrowing Mammal. University of Chicago Press, Chicago.

Huntly, N., Inouye, R., 1988. Pocket gophers in ecosystems: patterns \& mechanisms. BioScience 38, 786-793.

Hurlbert, S.H., 1984. Pseudoreplication \& the design of ecological field experiments. Ecological Monographs 54, $187-211$.

Jones, C.G., Lawton, J.H., Shachak, M., 1994. Organisms as ecosystem engineers. Oikos 69, 373-386.

Jones, C.G., Lawton, J.H., Shachak, M., 1997. Positive \& negative effects of organisms as physical ecosystem engineers. Ecology 78, 1946-1957.

Kierstead, J.R., 1981. Flora of Petrified Forest National Park, Arizona. MS Thesis, Northern Arizona University, Flagstaff.

Knowles, C.J., Stoner, C.J., Gieb, S.P., 1982. Selective use of black-tailed prairie dog towns by mountain plovers. Condor 84, 71-74.

Kotliar, N.B., 2000. Application of the new keystone-species concept to prairie dogs: how well does it work? Conservation Biology 14, 1715-1721.

Kotliar, N.B., Baker, B.W., Whicker, A.D., Plumb, G., 1999. A critical review of assumptions about the prairie dog as a keystone species. Environmental Management 24, 177-192.

Kremen, C., Caldwell, R.K., Erwin, T.L., Murphy, D.D., Noss, R.F., Sanjayan, M.A., 1993. Terrestrial arthropod assemblages: their use in conservation planning. Conservation Biology 7, 796-808.

Krueger, K., 1986. Feeding relationships among bison, pronghorn, and prairie dogs: an experimental analysis. Ecology 67, 760-770.

Kruskal, J.B., 1964. Multidimensional scaling by optimizing goodness of fit to a nonmetric hypothesis. Psychometrika 29, 1-27.

Legendre, P., Legendre, L., 1998. Numerical Ecology, second ed. Elsevier, Amsterdam.

Lill, J.T., Marquis, R.J., 2003. Ecosystem engineering by caterpillars increases insect herbivore diversity on white oak. Ecology 84, 682-690.

Lomolino, M.V., Smith, G.A., 2003. Terrestrial vertebrate communities at black-tailed prairie dog (Cynomys ludovicianus) towns. Biological Conservation 115, 89-100.

Martinsen, G.D., Cushman, J.H., Whitham, T.G., 1990. Impact of pocket gopher disturbance on plant species diversity in a shortgrass prairie community. Oecologia 83, 132-138.

Martinsen, G.D., Floate, K.D., Waltz, A.M., Wimp, G.M., Whitham, T.G., 2000. Positive interactions between leafrollers and other arthropods enhance biodiversity on hybrid cottonwoods. Oecologia 123, 82-89.

Miller, S.D., Cully Jr., J.F., 2001. Conservation of black-tailed prairie dogs (Cynomys ludovicianus). Journal of Mammalogy 82, 889-893.

Miller, B., Reading, R., Hoogland, J., Clark, T., Ceballos, G., List, R., Forrest, S., Hanebury, L., Manzano, P., Pacheco, J., Uresk, D., 2000. The role of prairie dogs as a keystone species: response to Stapp. Conservation Biology 14, 318-321.

Minchin, P.R., 1987. Simulation of multidimensional community patterns: towards a comprehensive model. Vegetation 71, 145-156. 
Minchin, P.R., 1999. DECODA: Database for Ecological Community Data. Version 3.00 b06. Australian National University, Canberra.

Munn, L.C., 1993. Effects of prairie dogs on physical and chemical properties of soils. In: Oldemeyer, J.L., Biggins, D.E., Miller, B.J., Crete, R. (Eds.), Proceedings of the symposium on the management of prairie dog complexes for the reintroduction of the black-footed ferret. US Department of the Interior Fish and Wildlife Service, Washington, DC, pp. 11-17 Biological Report 13.

Oldemeyer, J.L., Biggins, D.E., Miller, B.J., Crete, R. (Eds.), 1993. Proceedings of the symposium on the management of prairie dog complexes for the reintroduction of the black-footed ferret. US Department of the Interior Fish and Wildlife Service, Washington, DC Biological Report 13.

O’Meilia, M.E., Knopf, F.L., Lewis, J.C., 1982. Some consequences of competition between prairie dogs and beef cattle. Journal of Range Management 35, 580-585.

Parmelee, R.W., 1995. Soil fauna: linking different levels of the ecological hierarchy. In: Jones, C.J., Lawton, J.H. (Eds.), Linking Species and Ecosystems. Chapman \& Hall, New York, pp. 107-116.

Parmenter, R.R., Parmenter, C.A., Cheney, C.D., 1989. Factors influencing microhabitat partitioning in arid-land darkling beetles (Tenebrionidae): temperature and water conservation. Journal of Arid Environments 17, 57-67.

Power, M.E., Tilman, D., Estes, J.A., Menge, B.A., Bond, W.J., Mills, L.S., Daily, G., Castilla, J.C., Lubchencko, J., Paine, R.T., 1996. Identifying keystone species is difficult but essential to understanding how loss of species will affect ecosystems. BioScience 46, 609-620.

Riddle, W.A., Crawford, C.S., Zeiton, A.M., 1976. Patterns of hemolymph osmoregulation in three desert arthropods. Journal of Comparative Physiology 112, 295-305.

Schmidt-Nielson, B., Schmidt-Nielson, K., 1950. Evaporative water loss in desert rodents in their natural environment. Ecology 31, 75-85.

Seastedt, T.R., 1984. The role of microarthropods in decomposition and mineralization processes. Annual Review of Entomology 29, 25-46.

Shalaway, S., Slobodchikoff, C.N., 1988. Seasonal changes in the diet of the Gunnison's prairie dog. Journal of Mammalogy 69, 835-841.

Simberloff, D., 1998. Flagships, umbrellas, and keystones: is single species management passé in the landscape era? Biological Conservation 83, 247-257.

Slobodchikoff, C.N., 1983. Water balance and temperature preferences, and their role in regulating activity times of tenebrionid beetles. Oikos 40, 113-119.

Slobodchikoff, C.N., 1984. Resources and the evolution of social behavior. In: Price, P.W., Slobodchikoff, C.N., Gaud, W.S. (Eds.), A New Ecology: Novel Approaches to Interactive Systems. Wiley, New York, pp. $227-251$.

Smith, G.A., Lomolino, M.V., 2004. Black-tailed prairie dogs and the structure of avian communities on the shortgrass plains. Oecologia 138, 592-602.

Stapp, P., 1998. A reevaluation of the role of prairie dogs in Great Plains grasslands. Conservation Biology 12 , 1253-1259.

Stewart-Oaten, A., Murdoch, W.W., Parker, K.R., 1986. Environmental impact assessment: “pseudoreplication” in time? Ecology 67, 929-940.

Stewart-Oaten, A., Bence, J.R., Osenberg, C.W., 1992. The effects of unreplicated perturbations: no simple solutions. Ecology 73, 1396-1404.

Su, J.C., Debinski, D.M., Jakubauskas, M.E., Kindscher, K., 2004. Beyond species richness: community similarity as a measure of cross-taxon congruence for course-filter conservation. Conservation Biology 18, $167-173$.

Vogel, S., Ellington Jr., C.P., Kilgore Jr., D.L., 1973. Wind-induced ventilation of the burrow of the prairie dog, Cynomys ludovicianus. Journal of Comparative Physiology 85, 1-14.

Weltzin, J.F., Archer, S., Heitschmidt, R.K., 1997a. Small-mammal regulation of vegetation structure in a temperate savanna. Ecology 78, 751-763.

Weltzin, J.F., Downhower, S.L., Heitschmidt, R.K., 1997b. Prairie dog effects on plant community structure in southern mixed-grass prairie. Southwestern Naturalist 42, 251-258.

Whicker, A.D., Detling, J.K., 1988. Ecological consequences of prairie dog disturbances: prairie dogs alter grassland patch structure, nutrient cycling, and feeding-site selection by other herbivores. BioScience 38 , $778-785$.

Whicker, A.D., Detling, J.K., 1993. Control of grassland ecosystem processes by prairie dogs. In: Oldemeyer, J.L., Biggins, D.E., Miller, B.J., Crete, R. (Eds.), Proceedings of the symposium on the management of prairie dog 
complexes for the reintroduction of the black-footed ferret. US Department of the Interior Fish and Wildlife Service, Washington, DC, pp. 18-27 Biological Report 13.

Whicker, A.D., Tracy, C.R., 1987. Tenebrionid beetles in the shortgrass prairie: daily and seasonal patterns of activity and temperature. Ecological Entomology 12, 97-108.

Wimp, G.M., Martinsen, G.D., Floate, K.D., Bangert, R.K., Whitham, T.G., 2005. Plant genetic determinants of arthropod community structure and diversity. Evolution 59, 61-69.

Wright, J.P., Jones, C.G., Flecker, A.S., 2002. An ecosystem engineer, the beaver, increases species richness at the landscape scale. Oecologia 132, 96-101. 